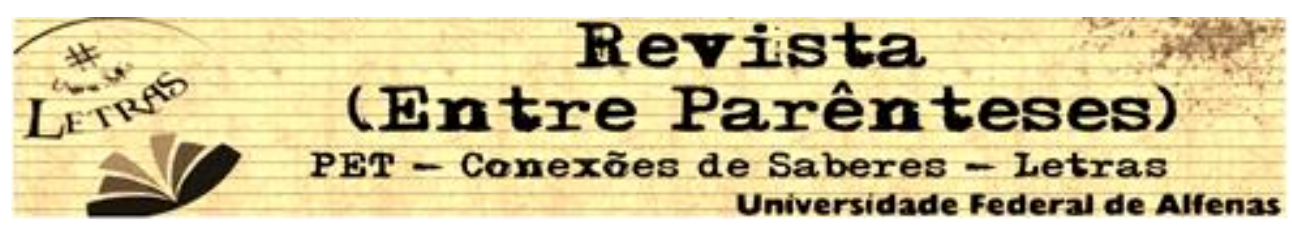

\title{
O FANTÁSTICO NO CONTO “TELECO, O COELHINHO”, DE MURILO RUBIÃO: ESTILO LITERÁRIO DO ESCRITOR
}

\author{
Breno Oliveira Correia ${ }^{1}$ \\ Graduando Universidade Federal de Alfenas (UNIFAL-MG) \\ (brennocontabilidade@gmail.com) \\ Aparecida Maria Nunes ${ }^{2}$ \\ Universidade Federal de Alfenas (UNIFAL-MG) \\ (cydamaria@gmail.com)
}

\begin{abstract}
Resumo: A pesquisa científica aqui apresentada visa demonstrar alguns aspectos da presença do fantástico no conto "Teleco, o coelhinho", do escritor contemporâneo Murilo Rubião, mineiro de Carmo de Minas. Rubião, nascido em 1916, não seguiu o caminho da escrita por acaso. Seu avô e seu pai foram escritores; além de seu primo, Godofredo Rangel, membro da Academia Mineira de Letras. Rubião, no entanto, iniciou seus estudos no interior do Estado e já no ensino médio estava em Belo Horizonte, onde cursou Direito. Ainda na faculdade, envolveu-se em atividades ligadas ao jornalismo e à literatura. Todas suas narrativas se relacionam com as leituras da Bíblia, inclusive o conto "Teleco, o coelhinho", objeto de estudo deste artigo. O conto narra a respeito de um coelho falante que se transforma em outros animais em busca da própria identidade. A metamorfose está presente do início ao fim. O fantástico é gênero que não se permite definir facilmente. É pouco adotado na literatura brasileira contemporânea. Poucos escritores se interessariam pelas narrativas de um coelho falante que se transforma em outros animais em busca da própria identidade, seguindo a mobilidade dos seus desejos. Contos como "Teleco, o coelhinho" criam situações desconcertantes, levando o leitor a perpetuar num mundo desconhecido da realidade.
\end{abstract}

Palavras-chave: O fantástico em Murilo Rubião; O conto muriliano; Literatura Contemporânea.

\begin{abstract}
The scientific research presented here aims to demonstrate some aspects of the presence of the Fantastic in the short story "Teleco o coelinho", by the contemporary writer Murilo Rubião - a mineiro citizen from Carmo de Minas, Brazil. Rubião, born in 1916, did not follow the path of writing only by chance. Your grandfather and your father were writers, and his cousin Godofredo Rangel, a member of the Academia Mineira de Letras (Minas Gerais Academy of Letters). Rubião, however, began his studies in the interior of the State and already in high school was in Belo Horizonte, where he graduated in Law School. Still in college, he involved himself in activities linked to journalism and literature. All his narratives relate to Bible readings, including the short story "Teleco o coelinho", the object of study of this article. The narrative tells of a talking rabbit that turns into other animals in search of their own identity. This metamorphosis is present from beginning to end. The Fantastic is a genre that you can't easily define and is little adopted in contemporary Brazilian literature. Few writers would be interested in the narratives of a talking rabbit that turns into other animals in search of their own identity, following the mobility of their desires. Stories like "Teleco o coelinho" create baffling situations that can make the reader perpetuate in an unknown world of reality.
\end{abstract}

Keywords: The Fantastic in Murilo Rubião; Conto muriliano - Murilian tale; Contemporary Literature.

\footnotetext{
${ }^{1}$ Graduando em Letras pela Universidade Federal de Alfenas - UNIFAL/MG.

2 Pós-doutorada em Estudos Literários pela Universidade Federal de Minas Gerais e doutora em Literatura Brasileira pela Universidade de São Paulo.
} 


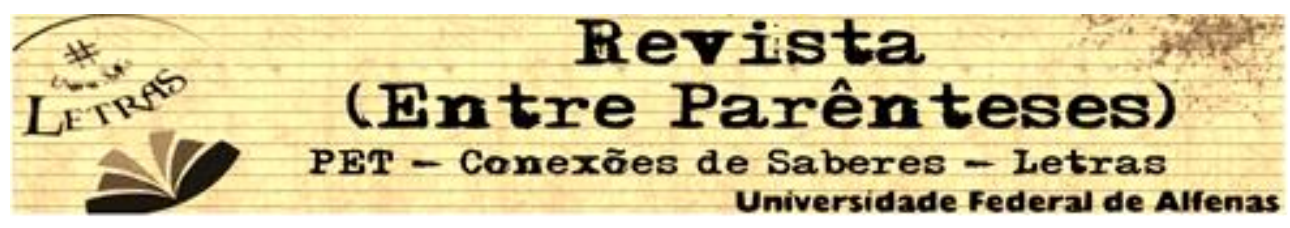

Resumen: La investigación científica aquí presentada pretende demostrar algunos aspectos de la presencia de lo fantástico en el cuento "Teleco, o coelhinho", del escritor contemporáneo Murilo Rubião. Rubião, nació en 1916, en la ciudad de Carmo de Minas, Minas Gerais, Brasil, no siguió el camino de la escritura por casualidad. Su abuelo y su padre fueron escritores; además de su primo, Godofredo Rangel, miembro de la Academia Mineira de Letras. El autor, sin embargo, inició sus estudios en el interior e ya en la enseñanza media estaba en Belo Horizonte, la capital del estado, donde cursó Derecho. Aún en la facultad, se involucró en actividades ligadas al periodismo y a la literatura. Todas sus narrativas se relacionan con las lecturas de la Biblia, incluso el cuento "Teleco, o coelhinho", objeto de estudio de este artículo. El cuento narra acerca de un conejo hablante que se transforma en otros animales en busca de la propia identidad. La metamorfosis está presente del principio hasta el final del cuento. El fantástico es UN género que no se permite definir fácilmente. Es poco adoptado en la literatura brasileña contemporánea. Pocos escritores están interesados por una narrativa sobre un conejo hablante que se transforma en otros animales en busca de la propia identidad, siguiendo la movilidad de sus deseos. Cuentos como "Teleco, o coelhinho" crean situaciones desconcertantes, llevando al lector a perpetuarse en un mundo desconocido de la realidad.

Palabras-clave: El fantástico en Murilo Rubião; El cuento muriliano; Literatura Contemporánea.

\section{INTRODUÇÃO}

O mundo do realismo fantástico é um campo que sempre me despertou interesses. Foi um fascínio inexplicável, talvez por ser um gênero que até então eu não tivesse o mínimo de conhecimento. Meu primeiro contato real com este estilo literário narrativo se deu a partir da leitura dos livros "Cem anos de solidão" (1967) e "O amor nos tempos do cólera" (1985), do escritor colombiano, Gabriel García Marquez, mesmo tendo surgido depois de Murilo Rubião. Outro contato marcante que foi fundamental para aguçar minha curiosidade para com este estilo literário narrativo, foi a leitura do conto de fada "Alice no país das maravilhas", de Lewis Carroll, mesmo não abordando características reais dos contos de Rubião. No decorrer da minha graduação comecei a aprofundar um pouco mais no assunto, procurando entender o fascínio do fantástico, foi então que conheci a obra completa do contista Murilo Rubião. Logo assim, o fantástico, com caráter especial ao conto "Teleco, o coelhinho", tornou-se objeto de estudo da pesquisa aqui desenvolvida.

O realismo fantástico é a característica marcante da obra completa do contista mineiro, responsável por um estilo único, que não deixou seguidores na literatura brasileira. Rubião surpreende sempre seus leitores por acontecimentos e fatos alicerçados em hipóteses "impossíveis" de se concretizarem na vida real, porém marcados pela verossimilhança, ou seja, há uma lógica plausível na construção do 


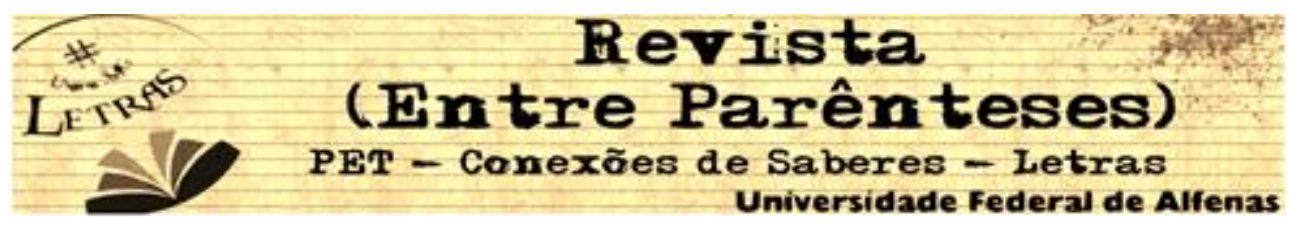

enredo, firmando, assim, sua inovação na literatura brasileira, expandindo os gêneros literários. Porém, esse diferencial não favoreceu seu ponto engajamento na literatura brasileira e muito tempo discorreu para cair no gosto da crítica. Antes da publicação de seu primeiro livro, sofreu bastantes rejeições por parte das editoras, principalmente pelo fato de trabalhar um gênero narrativo raramente difundido no Brasil.

Rubião não pôde contar com uma editora cuja impressão fosse de qualidade, nem mesmo com um bom trabalho de divulgação. Sendo assim, o contista mineiro demorou a ser reconhecido na literatura brasileira:

O sucesso de Murilo Rubião, no entanto, só viria em 1974, quando se publicaram $O$ convidado e $O$ pirotécnico Zacarias, (...). É esse 0 momento em que o escritor se torna efetivamente conhecido e sua obra passa a ser divulgada, principalmente, devido à sua indicação para concursos vestibulares (Cf. GOULART, 1995, p.9).

Até então, o fantástico era um gênero pouco conhecido. Essa opção pelo insólito, lembra uma citação:

Se num determinado período de minha atividade literária senti certa atração pelos contos populares e as histórias de fadas, isso não se deveu à fidelidade a uma tradição étnica (...), nem por nostalgia de minhas leituras infantis (...), mas por interesse estilístico e estrutural, pela economia, o ritmo, a lógica essencial com que tais contos são narrados (Cf. CALVINO, 1990, p.49).

Nota-se que Murilo Rubião se identifica com o insólito ficcional assim como Calvino, ou seja, ambos atentos aos aspectos estilísticos do texto.

Murilo Rubião surge como o precursor da literatura fantástica no Brasil, gênero que até então era raro em nossas obras, pois não se encaixava nos parâmetros da literatura contemporânea do século $X X$, inclusive entre os hispanoamericanos. Razão por ter sido Rubião comparado a Franz Kafka, por exemplo.

Há diversas opiniões acerca do surgimento do gênero fantástico. De acordo com Rodrigues (1988), a maioria dos estudiosos considera o nascimento do fantástico 


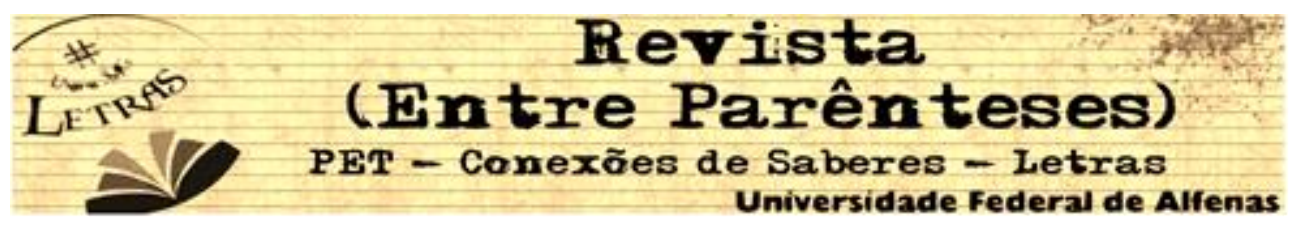

entre os séculos XVIII e XIX, tendo seu amadurecimento ocorrido no século XX. Contudo, é importante esclarecer, o fantástico não está em elencar aspectos absurdos no cotidiano. "O elemento extraordinário não se limita apenas a uma experiência de leitura prazerosa para efeitos de distração do leitor", podemos argumentar também. Mas a distinção está notadamente, no fato de assumir "uma função eminentemente crítica". (SCHWARTZ, 1982).

É oportuno dizer que, a perplexidade provocada dos contos de Murilo Rubião em seus leitores não impede que os fatos sobrenaturais narrados no conjunto de sua obra sejam aceitos, sem controvérsias, pelos mesmos. Partindo dessas considerações, traçaremos a análise da presente pesquisa de iniciação científica sobre o fantástico, presente nos trinta e três contos publicados de Rubião, mas, concentrando os estudos no conto "Teleco, o coelhinho".

\section{O FANTÁSTICO}

Há características marcantes e nítidas presentes na contística muriliana, sobretudo no que se refere ao absurdo e ao fantástico. Em especial, no conto "Teleco, o coelhinho", tais aspectos são determinantes, estando logo presentes nos primeiros parágrafos da narrativa, o que causa sutil estranhamento nos leitores, justamente por fugir aos parâmetros reais.

O que chama muita atenção no conto "Teleco, o coelhinho" é como o narrador conversa com o coelho, sem nenhuma admiração ou espanto, na maior naturalidade possível, como se fosse um animal racional e passível de consciência plena. Essa circunstância pontua a narrativa dos contos murilianos, levando-se em conta que as atitudes estranhas das personagens acabam por construir o enredo. Mas, é importante salientar, a fascinação do leitor, da introdução até o desfecho, pela espontaneidade dos acontecimentos narrados através de um texto fluente de Rubião.

O realismo fantástico, aspecto sempre recorrente na contística muriliana, delineia-se, segundo Santos, como um tipo literário no qual há subversão da ordem 


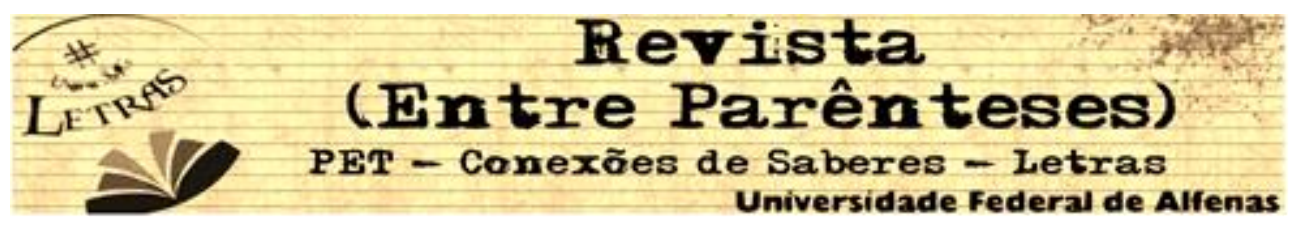

por meio de uma situação excêntrica. Isso significa, em outras palavras, que o real se faz presente; contudo, "desconhece os princípios lógicos e naturais que caracterizam o universo do racional" (2006, p. 4).

Por ser um gênero que sofreu e tem sofrido diversas modificações ao longo dos séculos, o realismo fantástico tem sido muito estudado e seus estudiosos o definem de formas diferentes. No entanto, algumas características são comuns a todos os estudos realizados, são elas, em suma, a evocação de emoções no leitor por meio de fatos sobrenaturais, a presença desses fatos sobrenaturais no cotidiano e a fusão do real e do irreal. Furtado (1980) aponta justamente o surgimento do sobrenatural em um ambiente cotidiano e familiar.

Segundo o teórico Irlemar Chiampi:

O fantástico contenta-se em fabricar hipóteses falsas (o seu "possível" é improvável), em desenhar a arbitrariedade da razão, em sacudir as convenções culturais, mas sem oferecer ao leitor, nada além da incerteza. A falácia das probabilidades externas e inadequadas, as explicações impossíveis - tanto no âmbito do mítico - se constroem sobre o artifício lúdico do verossímil textual, cujo projeto é evitar toda asserção, todo significado fixo. O fantástico "faz da falsidade o seu próprio objeto, o seu próprio móvil” (CHIAMPI, 1980, p. 56).

Para Todorov, num mundo que é exatamente o nosso, aquele que conhecemos (...) produz-se um acontecimento que não pode ser explicado pelas leis deste mundo familiar. Aquele que o percebe deve optar por uma das duas soluções possíveis; ou se trata de uma ilusão de sentidos, de um produto da imaginação e nesse caso as leis do mundo continuam a ser o que são; ou, então, o acontecimento realmente ocorreu, e é parte integrante da realidade, mas, nesse caso, esta realidade é regida por leis desconhecida de nós. (...) O fantástico ocorre nessa incerteza; ao escolher uma ou outra resposta, deixa-se o fantástico para se entrar num gênero vizinho, o estranho ou o maravilhoso. "O fantástico é a hesitação experimentada por um ser que só conhece as leis naturais, em face de um acontecimento aparentemente natural" (TODOROV, 1975, p 30-31).

Os fatos sobrenaturais não perpetuam somente no mundo do realismo

Revista (Entre Parênteses)
Volume 6, Número 2, 2017 - ISSN 2238-4502




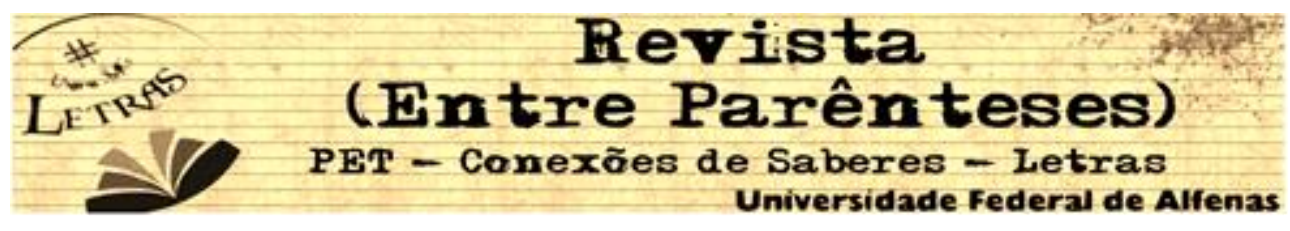

fantástico. Furtado (1980) ressalva que a temática do sobrenatural não é exclusiva do fantástico - o estranho e o maravilhoso também fazem parte do grande grupo da "literatura do sobrenatural" (p.20). O crítico ressalta, ainda, a existência do sobrenatural positivo e do sobrenatural negativo - o primeiro associado à ideia do Bem, e o segundo, ao conceito de Mal -, e declara: "só o sobrenatural negativo convém à construção do fantástico" (FURTADO, 1980, p.22). É bom lembrar que para Furtado, assim como para Todorov, o fantástico é um gênero "abordado como uma organização dinâmica de elementos que, mutuamente combinados ao longo da obra, conduzem a uma verdadeira construção de equilíbrio difícil" (FURTADO, 1980, p.15).

Portanto, a existência do fantástico está atrelada à permanência da dúvida, à hesitação diante do acontecimento sobrenatural. Sabemos que a metamorfose é um elemento essencial para o aparecimento do gênero fantástico, além de outros elementos como a hipérbole e a metáfora, entre outros. Neste caso temos a metamorfose do coelho como um acontecimento real, porém desconhecido por nós. A metamorfose é mais um artifício empregado pelo escritor para criticar o homem moderno. "Seus contos não se propõem a responder ou resolver as questões do mundo, ao contrário, são enigmas que conduzem à reflexão do real" (SANTOS, 2006, p.196).

Então, o conto em si apresenta várias ações impossíveis de acontecerem na vida real, porém tais situações surgem na história de forma tão lógica e natural que acabam convencendo-nos de que aquilo seja verdadeiro, ou seja, possível de acontecer. Portanto, para os leitores, Teleco é uma personagem inverossímil por apresentar conduta "estranha", mas é verossímil na narrativa fantástica.

O inverossímil na categoria do fantástico transita na realidade dos fatos, coadunando com a lógica a que os seres humanos estão submetidos. No dizer do crítico literário Antônio Cândido:

O que julgamos inverossímil, segundo padrões da vida corrente, é na verdade, incoerente, em face da estrutura do livro. Se no capacitarmos disto - graças à análise literária - veremos que, embora o vínculo com a vida, o desejo de representar o real, seja a chave mestre da eficácia

\begin{tabular}{l|c}
\hline Revista (Entre Parênteses) \\
Volume 6, Número 2, 2017 - ISSN 2238-4502
\end{tabular}




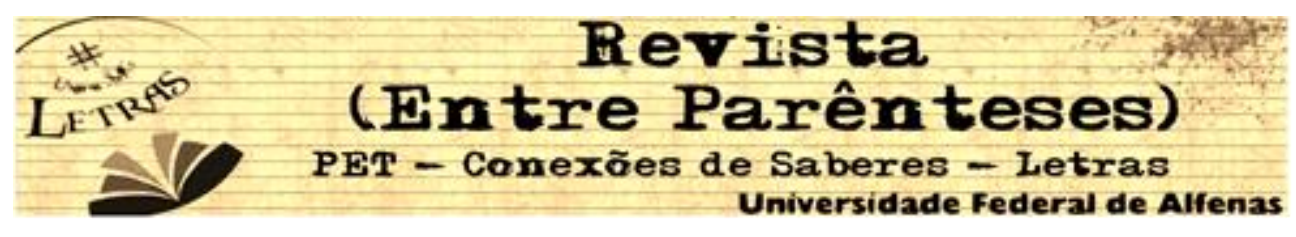

de um romance, a condição de seu pleno funcionamento, e, portanto do funcionamento das personagens, depende dum critério estético de organização externa. Se esta funciona, aceitaremos inclusive o que é inverossímil em face das concepções correntes. (1970, pp.76-77)

Analisando o conto "Teleco, o coelhinho" nota-se quão natural o coelho age no ambiente delimitado da narrativa. O primeiro estranhamento nos é causado quando o animalzinho surge ao homem na praia, pedindo um cigarro, com indícios de uma boa educação: “Moço, oh! Moço! Moço, me dá um cigarro?” (p 52). Esse fato alimenta extraordinariamente a nossa percepção quanto aos fatos sobrenaturais que ocorrem na realidade que supomos conhecer, causando perplexidade e uma grande curiosidade no leitor que perpetua em um mundo insólito, porém possível e aceito pela realidade. Leva-se em conta que as atitudes estranhas dos personagens é que são responsáveis pela construção do enredo. Porém, é bom lembrar sempre quão espontâneos são os acontecimentos pertinentes nos contos murilianos.

Mediante as metamorfoses do coelhinho, Murilo Rubião chama a atenção para as atitudes dos homens. Segundo o autor, a humanidade está se "desumanizando", caindo em terríveis vícios que aferem a conduta da sociedade em geral. Teleco queria sempre agradar as pessoas, por isso aparecia de um jeito para, logo em seguida, alterar para outro, seguindo a mobilidade de seus desejos. Tais metamorfoses são as consequências dos sentimentos de Teleco, ao revelar e exteriorizar o que pensou ou sentiu. Seria um pretexto de reação devidamente adversa às falhas tentativas de humanizar os homens. Sendo assim, podemos afirmar que Murilo Rubião buscou nas imagens surreais e no absurdo os meios para desmascarar a hipocrisia social e retratar os conflitos existenciais do homem moderno, preso ao cotidiano.

As metamorfoses tornam-se, então, incontroláveis pelo fato de o ser humano ser abominável e pérfido. Como Teleco reage contrariando essa condição, o "organismo" dele responde drasticamente com o intuito de promover, a nós leitores, as sensações angustiantes, que $o$ animal sente, ao não poder fazer nada para que a realidade do ser humano seja demudada.

\begin{tabular}{l|c}
\hline Revista (Entre Parênteses) \\
Volume 6, Número 2, 2017 - ISSN 2238-4502
\end{tabular}




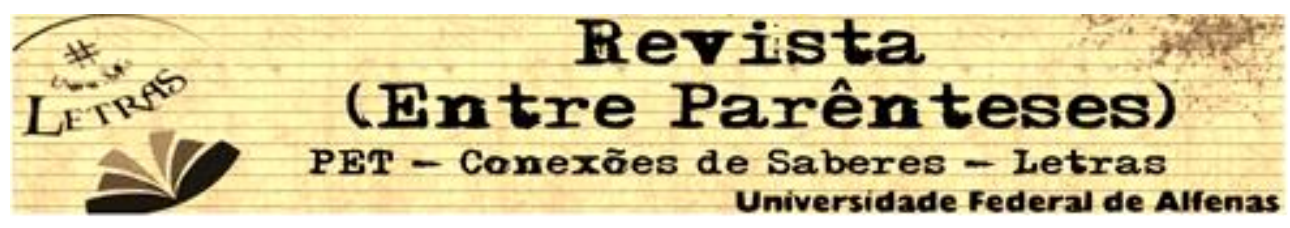

Seguindo essa vertente, é notória a visibilidade que temos no início da narrativa, quando o coelhinho esbanja a sua inocência na tentativa, vã, de agradar as pessoas e, por fim, ao considerar-se homem, assume todas as maldades que as pessoas são capazes de cometerem. Sendo assim, as metamorfoses de Teleco compõem, nesse caso, o realismo fantástico do conto em si. Por outro lado, a vivência do narrador com o coelhinho é destacada intensamente pelo autor. A transmutação do animal, no anseio de sempre agradar quem está no seu entorno, indica a necessidade de aceitação pelo social, e, com isso, indícios de uma personalidade que ainda não conhece o seu "eu". Portanto, Murilo trabalha seu fantástico conforme outros moldes, novas experimentações, o que levou o crítico Schwartz a argumentar:

Em Murilo Rubião, o fantástico está no cotidiano. Ausência de rupturas bruscas na sequência narrativa ou de efeito de suspense no leitor. Acontecimentos referencialmente antagônicos e inconciliáveis conciliam-se tranquilamente pela organização da linguagem. Dragões, coelhos e cangurus falam, mas não há mais o clássico "enigma" a ser desvendado no final. (SCHWARTZ, 2004, p. 08)

Murilo Rubião, por outro lado, dá o capricho à sua obra sempre levando em consideração questões bíblicas, cujas leituras, apesar de ser agnóstico, o acompanham desde menino. Há uma relação nos contos dele com os ensinamentos dos evangelhos que apontam, via de regras, para fatos sociais e humanos a serem discutidos pelo leitor.

O desfecho, por exemplo, do conto do coelhinho Teleco nos permite concluir que não há salvação para o homem. Por mais que o coelhinho metamorfoseia-se em distintos animais, ele acaba por fim sendo uma criança sem dentes, morta nos braços do narrador. A ingenuidade que exalava o coelhinho acaba sendo corrompida pela imperfeição natural da raça humana. Ou seja, os animais são metamorfoses dos humanos que, metamorfoseado, entretanto permanece humano, igual a si mesmo, sem chance de sair da condenação. No conto "Teleco, o coelhinho", a metamorfose constitui, então, o tema principal, aliás, como recorrente na obra do escritor mineiro, vê-se que o tema de multiplicação também se revela assíduo em sua 


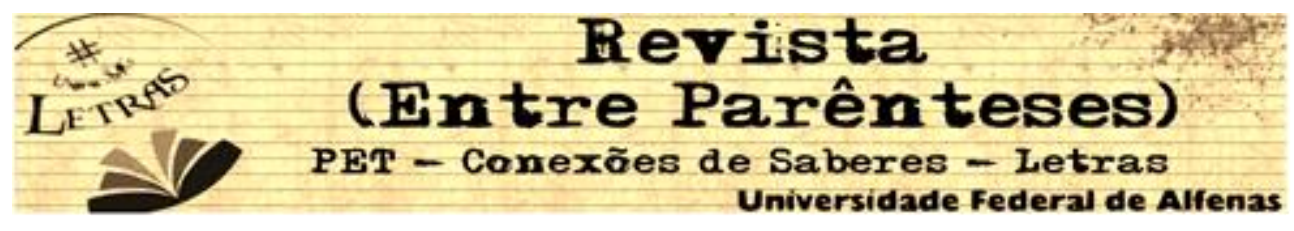

obra.

\section{CONSIDERAÇÕES FINAIS}

Percebe-se que na narrativa fantástica há, ao mesmo tempo, uma aproximação, no sentido estrito de aliança, e, também, distanciamento, no sentido de oposição, entre as ordens do real e do sobrenatural. Com isso, ocorrem fenômenos como a ambiguidade, manifestação de incertezas dos fenômenos sobrenaturais e insólitos da narrativa, entre outros. Em "Teleco, o coelhinho", as atitudes da personagem Teleco distanciam totalmente dessa realidade que supomos conhecer, mas, ao mesmo tempo há semelhanças com as atitudes dos seres humanos que consideremos comuns, ou seja, fatos corriqueiros presentes no dia a dia. É através da metamorfose que o animal busca a sua própria identidade. Isso causa tamanha confusão entre leitores, que mesmo com tamanhas "façanhas" do coelho, acabam aceitando os acontecimentos estranhos de uma forma natural, ou seja, aceitamos como verossímil as metamorfoses. Nota-se, então, que a narrativa fantástica de Rubião é trabalhada em cima de fatos e ações do cotidiano, com seres reais, comuns da realidade, diferente do realismo mágico que trabalha com seres imaginários ou fictícios. Esses seres comuns são os animais (coelho, canguru), o homem que abriga Teleco etc. As ações cotidianas são marcadas pelas atividades do dia a dia, como, um diálogo entre as personagens, uma briga comum entre eles, a rotina de trabalho da personagem, as emoções à flor da pele etc. Os espaços onde acontece a narrativa são comuns. A maioria das cenas acontece na praia ou na casa do homem que está sempre em diálogo com Teleco. O autor também sempre marca o tempo, por exemplo, se é dia ou se é noite.

O homem conversa naturalmente com Teleco, como se estivesse em diálogo com outro ser humano, na mais perfeita normalidade, apenas sente uma grande admiração ao perceber que o coelho é falante e que age segundo os seus desejos. Claro que a personagem que está em diálogo com o coelho habita um mundo 


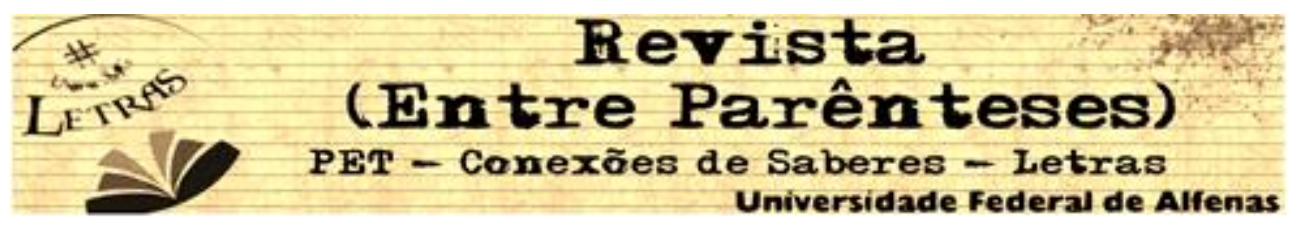

insólito, porém, toma como natural e real os acontecimentos que a realidade dele define como o sobrenatural e irreal.

A literatura em geral tende a se diversificar em distintos focos de interesse por parte dos leitores. Há gostos variados e estudos infinitos relacionados às obras que hoje estão disponíveis a todos. Muitas dessas narrações acabam "selecionando" um determinado grupo que se identifica mais com seus traços característicos, a fim de estudá-los em todos os âmbitos possíveis. Assim sendo, cada leitor se familiariza com seu gênero predileto. Portanto, é importante e fundamental que haja a diversidade de gêneros, como apresenta nossa literatura. O fantástico também é um desses gêneros que agrada uma parcela considerável dos leitores e, por isso, é necessário o estudo aprofundado de suas características e de seus traços.

De fato, a essência do fantástico reside na sua capacidade de expressar o sobrenatural de uma forma convincente e de manter uma constante e nunca resolvida dialética entre ele e o mundo natural em que irrompe, sem que o texto alguma vez explicite se aceita ou exclui inteiramente a existência de qualquer deles (FURTADO, 1980, p. 36).

Com o realismo fantástico, não é diferente. A análise que foi proposta aqui atrairá leitores dispostos a interagir com o mundo de fantasias e acontecimentos sobrenaturais, que podem causar, constantemente, espanto ou estranheza. Contudo e sincronicamente, esse estilo de narrativa convida ao prazer expressivo, quando 0 leitor se depara com as façanhas das personagens, com suas artimanhas, ou com as metamorfoses do coelhinho no conto, que sustentam as ações surreais presentes no enredo. O estudo deste gênero, portanto, é de fundamental importância para a literatura brasileira, pois, além de ressaltar o revigoramento da narrativa contemporânea, da qual Murilo Rubião não deixou herdeiros, resgata o interesse de leitores para um olhar atento sobre nossa condição humana. Além, é claro, de conhecer sobre a vida desse ficcionista, nascido em Silvestre Ferraz, hoje conhecida como Carmo de Minas, no Estado de Minas Gerais.

\begin{tabular}{l|c}
\hline Revista (Entre Parênteses) \\
Volume 6, Número 2, 2017 - ISSN 2238-4502
\end{tabular}




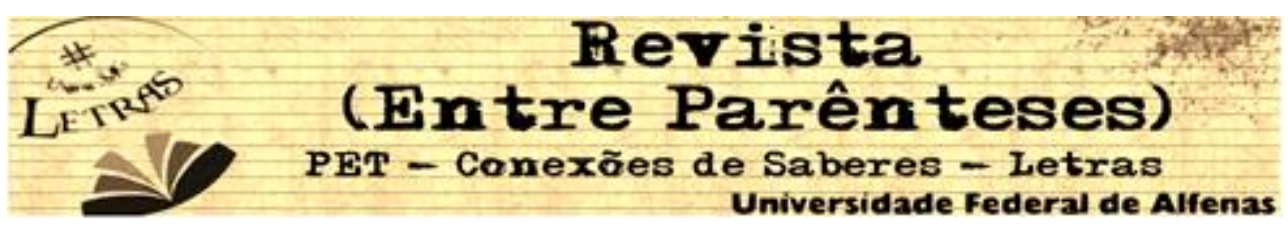

\section{REFERÊNCIAS}

CALVINO, Ítalo. Seis propostas para o novo milênio: lições americanas. Trad. Ivo Barroso. São Paulo: Companhia das Letras, 1990.

CÂNDIDO, Antônio et alli. A Personagem de ficção. São Paulo: Editora Perspectiva, 1970.

CHIAMPI, Irlemar. O Realismo Maravilhoso. São Paulo: Perspectiva, 1980.

FURTADO, Filipe. A construção do fantástico na narrativa. Lisboa: Livros Horizonte, 1980.

GOULART, Audemaro Taranto. O conto fantástico de Murilo Rubião. Belo Horizonte, MG: Lê, 1995.

RUBIÃO, Murilo. Obra Completa. $8^{a}$ reimpressão. São Paulo: Companhia de Bolso, 2015.

RODRIGUES, Selma Calasans. O Fantástico. São Paulo: Ática, 1988.

SANTOS, Luciane Alves. A metamorfose nos contos fantásticos de Murilo Rubião. Nau Literária, v. 2, n. 2, 2006.

SCHWARTZ, Jorge. (Org.). Murilo Rubião. São Paulo: Abril Educação, 1982.

SCHWARTZ, Jorge. O fantástico em Murilo Rubião. Revista Planeta: São Paulo. № 25, 2004.

TODOROV, Tzvetan. Introdução à literatura fantástica. Trad. Maria Clara Correa Castello. São Paulo: Perspectiva, 1975. 